\title{
Mycorrhizal Compatibility and Germination-Promoting Activity of Tulasnella Species in Two Species of Orchid (Cymbidium mannii and Epidendrum radicans)
}

\author{
Qianyu Yang ${ }^{1,2}$, Lijun Xu ${ }^{1}$, Wei Xia ${ }^{3}$, Lixiong Liang ${ }^{1}$, Xiao Bai ${ }^{1}, \operatorname{Lubin~Li}^{1}{ }^{1}, \mathrm{Lu} \mathrm{Xu}^{3, *}$ and Lei Liu ${ }^{1, *}$ \\ 1 State Key Laboratory of Forest Genetics and Tree Breeding, Key Laboratory of Silviculture of the State \\ Forestry Administration, Research Institute of Forestry, Chinese Academy of Forestry, Beijing 100091, China; \\ 2018500017@syau.edu.cn (Q.Y.); xulijun19935@126.com (L.X.); 11x0613@126.com (L.L.); \\ baixiao1004@163.com (X.B.); lilubin@126.com (L.L.) \\ 2 College of Forestry, Shenyang Agriculture University, Shenhe District, Shenyang 110866, China \\ 3 Hunan Mid-Subtropical Quality Plant Breeding and Utilization Engineering Technology Research Center, \\ College of Horticulture, Hunan Agricultural University, Changsha 410128, China; xiawei9712@163.com \\ * Correspondence: xulu@hunau.edu.cn (L.X.); liulei519@caf.ac.cn (L.L.)
}

check for updates

Citation: Yang, Q.; Xu, L.; Xia, W.; Liang, L.; Bai, X.; Li, L.; Xu, L.; Liu, L. Mycorrhizal Compatibility and Germination-Promoting Activity of Tulasnella Species in Two Species of Orchid (Cymbidium mannii and Epidendrum radicans). Horticulturae 2021, 7, 472. https://doi.org/10.3390/ horticulturae7110472

Academic Editor: Stefano Ghignone

Received: 25 September 2021

Accepted: 3 November 2021

Published: 5 November 2021

Publisher's Note: MDPI stays neutral with regard to jurisdictional claims in published maps and institutional affiliations.

Copyright: (c) 2021 by the authors. Licensee MDPI, Basel, Switzerland. This article is an open access article distributed under the terms and conditions of the Creative Commons Attribution (CC BY) license (https:// creativecommons.org/licenses/by/ $4.0 /)$
Abstract: In nature, Orchidaceae seeds establish a relationship with orchid mycorrhizal fungi to obtain essential nutrients for germination. The orchids, Cymbidium mannii and Epidendrum radicans, have significant ornamental and economic value. We isolated and cultured mycorrhizal fungi from C. mannii, E. radicans, and C. goeringii roots. Three strains of fungi, Tulasnella calospora (Tca), T. asymmetrica (Tas), and T. bifrons (Tbi), were identified using ITS-rDNA sequencing. Their mycorrhizal compatibility, germination-promoting effects, and symbiosis with the seeds of $C$. mannii and $E$. radicans were studied in vitro using various concentrations of oatmeal agar (OA) medium. Tca exhibited significant seed-germination-promoting effects on C. mannii $(92.1 \%)$ and E. radicans (84.7\%) on 2.0 and $4.0 \mathrm{~g} / \mathrm{L} \mathrm{OA}$, respectively. For Tbi and Tas, the highest germination percentages were observed on $4.0 \mathrm{~g} / \mathrm{L} \mathrm{OA}$ in E. radicans $(73.60 \%$ and $76.49 \%$, respectively). Seed germination in C. mannii was enhanced by high oatmeal concentrations $(8.0$ and $12.0 \mathrm{~g} / \mathrm{L})$ during symbiosis with Tas, whereas Tbi had no effect regardless of OA concentration. Tca exhibited high compatibility with $C$. mannii and E. radicans, and the oatmeal concentration of the medium affected this compatibility. The findings of this study will aid in the propagation of endangered orchid species for conservation and commercial purposes using mycorrhizal technology.

Keywords: Cymbidium mannii; Epidendrum radicans; Tulasnella spp.; mycorrhizal fungi; symbiosis

\section{Introduction}

Orchidaceae is widely regarded as the largest and most diverse family of angiosperms, consisting of 17,000-35,000 species and encompassing $8 \%$ of all vascular plants [1,2]. Orchid seeds tend to be small and dust-like, and lack an endosperm [3]. Low seed germination and seedling survival rates are the main factors limiting the protection of endangered orchids [4]. Consequently, germination and protocorm development depend on compatible mycorrhizal fungi to obtain carbon, water, and nutrients under natural conditions [5-7]. Given this obligate requirement, at least in the early developmental stages, obtaining optimal sources of mycorrhizal fungi and understanding the patterns of orchid-mycorrhizal relationships may facilitate the conservation of threatened orchid species and are, therefore, important steps for seed-based orchid conservation [8-10].

Compatibility between mycorrhizal fungi and orchids has an important effect on successful symbiotic seed germination [11]. Almost all known orchid mycorrhizal symbionts belong to two orders of Basidiomycetes, Cantharellales and Sebacinales [2,12]. Species of Tulasnella (Basidiomycota) are the most commonly reported mycorrhiza-forming fungi in orchids in both temperate and tropical zones, and can promote seed germination in 
many orchid species [13-15]. Moreover, it has been found that several orchid species may exhibit a certain degree of specificity with mycorrhizal fungi during seed germination and growth [10,16-20]. For example, there is a low degree of specificity toward orchid species and nine different fungal partners [21], and the mycorrhizae associated with Dendrobium seedlings are host-specific.

Symbiotic seed germination is a popular tool for studying orchid-fungus specificity; it plays a role in the production of mycobiont-infected healthy seedlings, which are valuable for both horticultural and conservation purposes [22,23]. This technique is largely performed by co-cultivating fungi and orchid seeds on oatmeal agar (OA) medium under laboratory conditions [23,24]. Many experiments have demonstrated that mycorrhizal symbiosis can be established in vitro on OA medium including 2.5, 3.0, 4.0, and $10.0 \mathrm{~g} / \mathrm{L}$ oatmeal [8,24-27]. A previous study compared the effect of different oatmeal concentrations in OA on in vitro symbiotic seed germination, and it was found that the three OA concentrations tested $(1.0,5.0$, and $10.0 \mathrm{~g} / \mathrm{L})$ exhibited similar germination percentages [28]. However, in our previous work, the symbiotic seed germination of orchid-Tulasnella differed under different OA concentrations $(0.25,2.5$, and $5.0 \mathrm{~g} / \mathrm{L}) ; 2.5 \mathrm{~g} / \mathrm{L} \mathrm{OA}$ was found to be the most effective symbiotic medium [29]. Based on this, adjusting the concentration of the orchid-fungal co-culture medium will help us to screen and establish a good symbiotic environment.

Species belonging to the genus Cymbidium have diverse life forms; about $70 \%$ are epiphytic, whereas a minority are terrestrial or lithophytic [30,31]. However, in recent years, Cymbidium species have been excessively exploited by humans. Their habitat has been seriously damaged, and their distribution range has been sharply reduced. As their wild resources gradually decrease, these Cymbidium species are in danger of extinction [4]. Cymbidium mannii is an epiphytic orchid with important ornamental and medicinal value [31,32]. Epidendrum is widely distributed, contains both terrestrial and epiphytic species, and has great potential for commercialization. Epidendrum radicans is one of the most highly valued flowers, potentially exhibiting the longest vase life in the cut-flower industry. It thrives in the tropics and subtropics [33]. At present, all wild orchids worldwide are listed in the Convention on International Trade in Endangered Species of Wild Fauna and Flora (CITES), and it is essential to safeguard these resources for the future. In recent years, most studies on orchid-fungi symbiotic seed germination have been conducted in Dendrobium [10,34-36]. Relatively few studies are available on the promotion of seed germination in symbiotic Tulasnella-C. mannii [4] and Tulasnella-E. radicans. In this study, we established symbiotic relationships between three Tulasnella species (isolated from three orchid species, two epiphytic and one terrestrial) and two epiphytic orchids, C. mannii and E. radicans, under different OA concentrations. We aimed to evaluate (1) whether Tulasnella species are compatible with various orchid plants and can promote the seed germination; and (2) whether the concentration of oatmeal in the medium affects their compatibility and germination-promoting activity. The results of this study may provide more clues for exploring the relationship between orchids and mycorrhizal fungi and will provide information on the propagation of endangered orchid species for conservation [11].

\section{Materials and Methods}

\subsection{Fungal Isolation and Tulasnella Identification}

The original sources of the plant samples are listed in Table 1. Cymbidium mannii was collected from Xinglong tropical botanical garden, Wanning, Hainan Province, where the cultivation matrix was a proportioned mix of chopped bark, moss, and Portland stone with a 2:1:1 mixing ratio. Epidendrum radicans was collected from the South China Botanical Garden, Guangzhou, Guangdong Province, where the cultivation matrix was a proportioned mix of chopped bark, moss, and brick fragments with a 3:1:1 mixing ratio. Cymbidium goeringii is a terrestrial orchid, and was collected from Shaoxing, Zhejiang Province, China $\left(120^{\circ} 49^{\prime} \mathrm{E}, 2^{\circ} 92^{\prime} \mathrm{N}\right)$.

Three roots were collected from each plant and three plants were collected from each species. The roots were packed in zip-lock bags and transferred to the Laboratory of the 
Research Institute of Forestry, Chinese Academy of Forestry. Hand-cut sections of the roots were examined under a light microscope (Olympus BX41, Tokyo, Japan) to observe the presence of pelotons, and uncolonized tissue was removed. Colonized roots were washed under running tap water for 4-6 h, followed by immersion in 70\% ethanol for $30 \mathrm{~s}$. Further, the roots were immersed in $5.0 \%$ sodium hypochlorite solution for $4-5 \mathrm{~min}$. The samples were rinsed with sterile distilled water 3-4 times. The roots were cut into slices using a sterile blade, and the sections were placed onto potato dextrose agar (PDA, BD Difco 213400, NewYork, NY, USA) with $50 \mu \mathrm{g} / \mathrm{mL}$ streptomycin to inhibit bacterial growth. At the same time, after undergoing the same treatment, uncut roots were placed directly on the Petri dish without cutting to test the surface-sterilization effectiveness. Petri dishes were incubated at $25^{\circ} \mathrm{C}$ until colonies were observed. Fungi that grew from the cut wounds in the plant roots were selected and transferred to new PDA medium. Fungi colonies from the cultures of the original isolates were re-cultured on new PDA medium an additional 3 times (or more) until purified fungal strains were obtained [5,25,37].

Table 1. Sources of the orchid species from which the samples were collected.

\begin{tabular}{|c|c|c|c|c|}
\hline Isolates & Species & $\begin{array}{l}\text { NCBI Accession } \\
\text { Number of ITS } \\
\text { Sequence }\end{array}$ & $\begin{array}{l}\text { Deposit } \\
\text { Number }\end{array}$ & Original Plant \\
\hline Tca & $\begin{array}{l}\text { Tulasnella } \\
\text { calospora }\end{array}$ & OK413294 & СРCC 401,220 & $\begin{array}{c}\text { Cymbidium mannii } \\
\text { (epiphytic) }\end{array}$ \\
\hline Tas & $\begin{array}{c}\text { Tulasnella } \\
\text { asymmetrica }\end{array}$ & OK413349 & СРCC 401,221 & $\begin{array}{c}\text { Epidendrum radicans } \\
\text { (epiphytic) }\end{array}$ \\
\hline Tbi & Tulasnella bifrons & OK413293 & CGMCC 14,794 & $\begin{array}{c}\text { Cymbidium goeringit } \\
\text { (terrestrial) }\end{array}$ \\
\hline
\end{tabular}

The fungal mycelia were frozen using liquid nitrogen, and DNA was extracted using an E.Z.N.A ${ }^{\text {TM }}$ Fungal DNA Miniprep Kit (D3390-01, Omega, Guangzhou, China) according to the manufacturer's instructions. Amplification of the ITS sequence was performed using the universal primers ITS1 (5'-TCCGTAGGTGAACCTGCGG-3') and ITS4 $\left(5^{\prime}\right.$-TCCTCCGCTTATTGATATGC-3'). ITS sequences were compared to those in the NCBI GenBank database using the Basic Local Alignment Search Tool (BLAST), and the ITS sequences of the three strains were registered in GenBank (Table 1).

Well-characterized and closely related taxa identified in the BLAST searches were included in the phylogenetic analyses. Multiple sequence alignments of each ITS sequence were made using ClustalW packaged with the BioEdit Sequence Alignment Editor (Ibis Biosciences, Carlsbad, CA, USA). Phylogenetic trees were generated using maximum likelihood analysis (MEGA X) [38], and 1000 bootstrap replicates were performed to estimate the node reliability of the resulting trees.

The strains were deposited in the China General Microbiological Culture Collection Center (CGMCC) and China Pharmaceutical Culture Collection (CPCC).

\subsection{Seed Harvest}

The seeds of the orchids C. mannii and E. radicans were used in this study. Plants were maintained in a greenhouse at the Chinese Academy of Forestry (Beijing, China) under day/night temperatures of $24{ }^{\circ} \mathrm{C} / 18{ }^{\circ} \mathrm{C}, 65-75 \%$ relative humidity, and an 8-h day/16-h night photoperiod. The flowers of the plants were pollinated by hand in the greenhouse. Mature capsules of $C$. mannii and E. radicans (about four capsules from each species) were collected 4-6 months after pollination, just prior to dehiscence (Figure 1). 


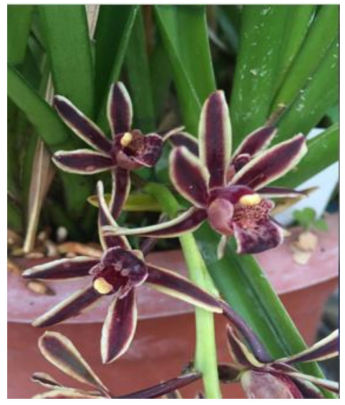

(a)

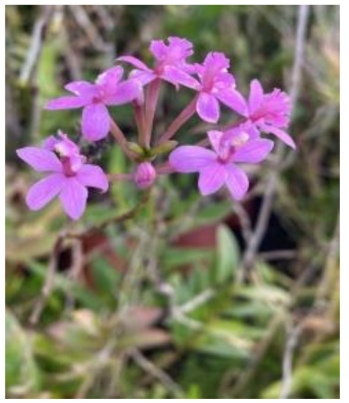

(d)

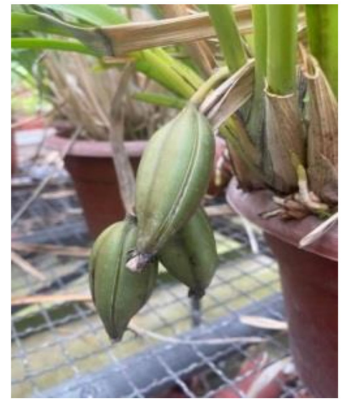

(b)

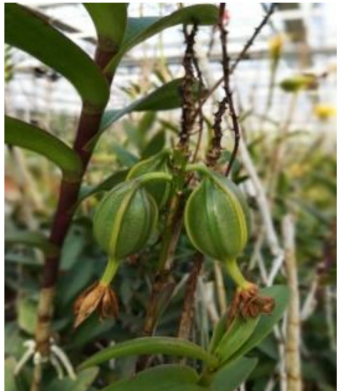

(e)

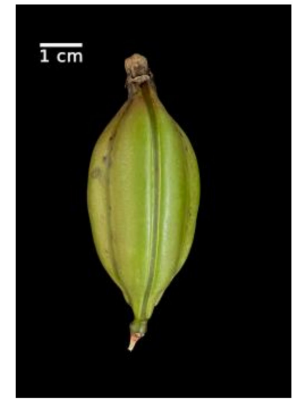

(c)

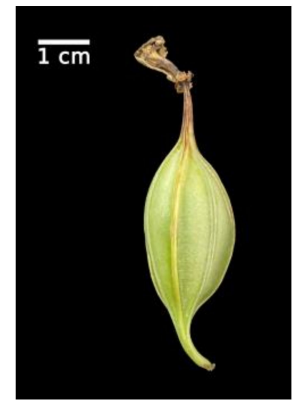

(f)

Figure 1. Flowers and capsules of Cymbidium mannii and Epidendrum radicans. (a) The flowers of $C$. mannii. $(\mathbf{b}, \mathbf{c})$ The capsules of $C$. mannii. (d) The flowers of E. radicans. (e,f) The capsules of E. radicans.

\subsection{Symbiotic Germination}

Orchid seed capsules were collected and then scrubbed with a soft brush under running tap water to remove any debris. Each capsule was further swabbed thoroughly thrice with $75 \%$ ethanol, disinfected with $5 \% \mathrm{NaClO}$ for 5-10 min, and rinsed thrice in sterile distilled water. The capsules were then incised longitudinally, and the dusty mature seeds picked out of them. Approximately 100-150 seeds were added to plates containing OA medium $[39,40]$. The concentrations of OA medium used were $0.5,1.0,2.0,4.0,8.0$, and $12.0 \mathrm{~g} / \mathrm{L}$. Cubes of about $1 \mathrm{~cm}^{3}$ of each fungal culture were transferred onto the surface of the OA medium.

The control treatment (CK group) contained no fungal inoculates. The plates were sealed with Parafilm (Bemis, Neenah, WI, USA) and maintained at day/night temperatures of $24^{\circ} \mathrm{C} / 18^{\circ} \mathrm{C}$ and $65-75 \%$ relative humidity. Each treatment consisted of 15 replicates.

\subsection{Assessment of the Fungal Capacity to Promote Seed Germination}

The seed germination and protocorm developmental stages were observed daily under a stereomicroscope (Nikon HFX, Tokyo, Japan). The toluidine blue colorimetric assay was performed to examine fungal colonization [34], and the timing of pelotonforming in the orchids was measured. Using the identified colonization times, data were subsequently collected 60 days after sowing to determine the growth index (GI) and percentage of seed germination. Seed germination status was assessed 60 days after incubation, and the standardized GI was calculated according to the criteria described by Otero [41]. The appearance of the promeristem was used as the primary criterion for defining germination [42].

The GI value was determined as follows: $\left(\mathrm{N}_{1}+\mathrm{N}_{2} \times 2+\mathrm{N}_{3} \times 3+\mathrm{N}_{4} \times 4+\mathrm{N}_{5} \times 5+\right.$ $\left.\mathrm{N}_{6} \times 6\right) /\left(\mathrm{N}_{0}+\mathrm{N}_{1}+\mathrm{N}_{2}+\mathrm{N}_{3}+\mathrm{N}_{4}+\mathrm{N}_{5}+\mathrm{N}_{6}\right)$. The germination rate (\%) was determined as follows: $\left(\mathrm{N}_{3}+\mathrm{N}_{4}+\mathrm{N}_{5}+\mathrm{N}_{6}\right) /\left(\mathrm{N}_{0}+\mathrm{N}_{1}+\mathrm{N}_{2}+\mathrm{N}_{3}+\mathrm{N}_{4}+\mathrm{N}_{5}+\mathrm{N}_{6}\right) \times 100$, where $\mathrm{N}_{0}$ is the number of seeds at stage $0, N_{1}$ is the number of seeds at stage 1 , and so on (Figure 2). 
Seeds can begin germinating, but then be unable to proceed beyond $\mathrm{N}_{3}$ to complete germination and successfully develop into seedlings. Therefore, even if the GI value is higher than zero, the germination rate could still be zero.

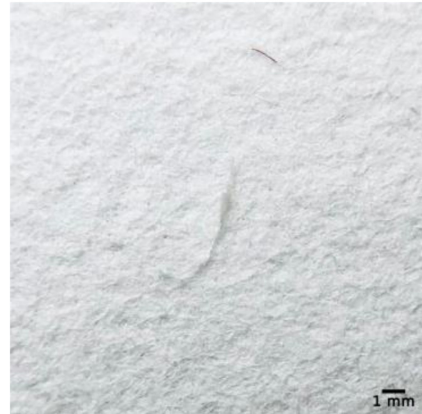

(a)

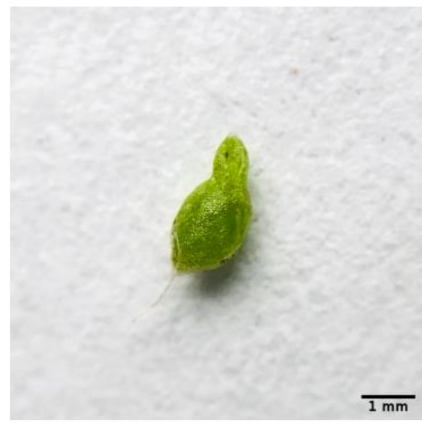

(d)

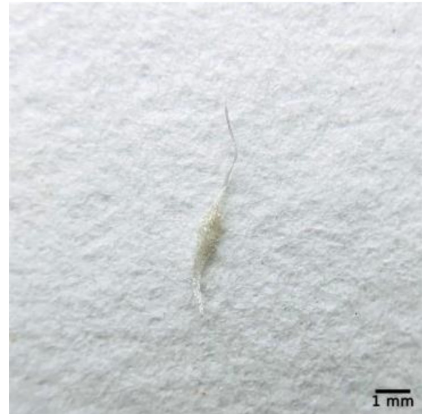

(b)

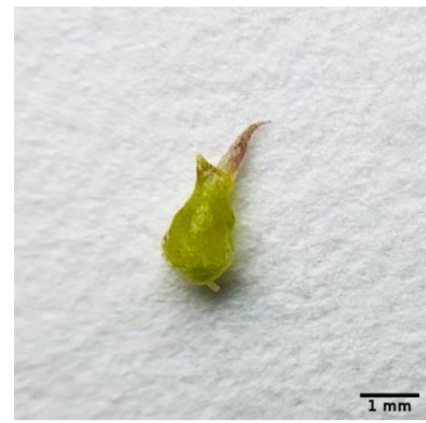

(e)

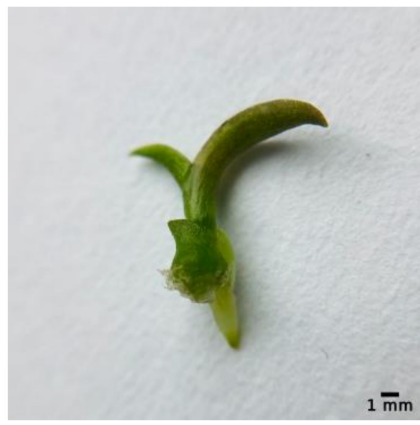

$(\mathrm{g})$

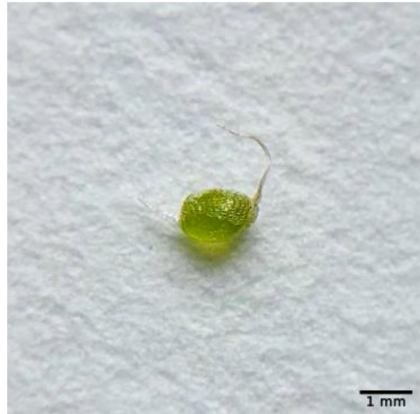

(c)

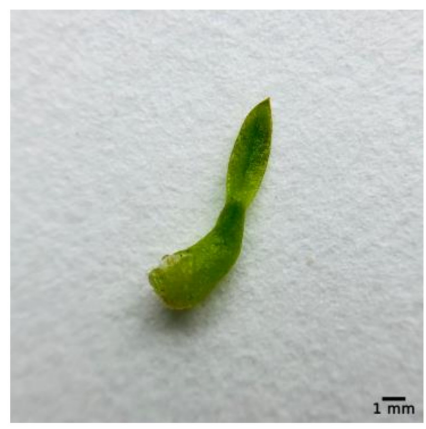

$(\mathbf{f})$

Figure 2. Stages in the development of E. radicans protocorms. (a) Stage $\mathrm{N}_{0}$, no germination. (b) Stage $\mathrm{N}_{1}$, production of rhizoids by the embryo. (c) Stage $\mathrm{N}_{2}$, rupture of testa by the enlarged embryo. (d) Stage $\mathrm{N}_{3}$, appearance of the promeristem. (e) Stage $\mathrm{N}_{4}$, appearance of the first true leaf. (f) Stage $\mathrm{N}_{5}$, elongation of the true leaf. (g) Stage $\mathrm{N}_{6}$, appearance of the second true leaf.

\subsection{Statistical Analysis}

All the experiments followed a completely randomized design. One-way ANOVA followed by Tukey's multiple comparison tests were performed to compare the germination rates and GI values among different treatments and to determine statistical significance $(p$ $<0.05)$. All statistical analyses were performed using R Studio software (version 1.4.1717).

\section{Results}

\subsection{Tulasnella Identification and Phylogenetic Analyses}

Mycorrhizal fungi were isolated from three orchid plants (Table 1). The ITS-5.8s rDNA sequences of the three isolates were found to be highly homologous with those of Tulasnella-like isolates, with $94-99 \%$ similarity in the NCBI gene database. Meanwhile, 
in the phylogenetic tree based on ITS-5.8s rDNA gene sequences using the maximumlikelihood method (Figure 3), the three strains were clustered with the clade comprising Tulasnella species. Strains Tca and Tbi were clustered with T. calospora strain MAFF P305802 (DQ388042) and T. bifrons specimen voucher BPI 724,849 (AY373290), respectively. Tas formed a phylogenetic lineage within the clade comprising the strain T. asymmetrica AL. PC10.6 (MH134557).

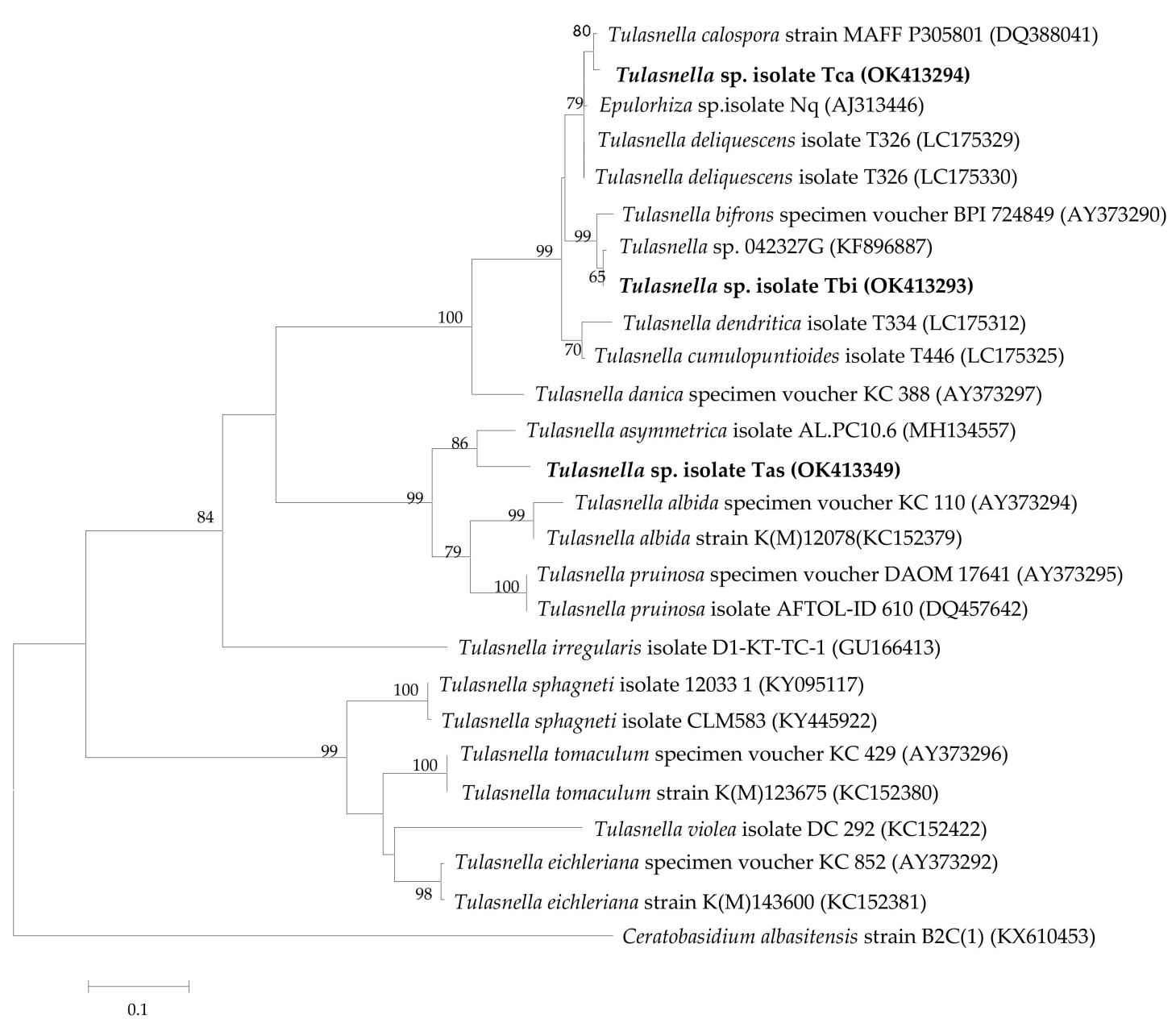

Figure 3. Maximum likelihood trees of ITS sequences of Tulasnella spp. The sequence of Ceratobasidium albasitensis strain B2C (1) was used as an outgroup. Bootstrap percentages (based on 1000 replications) $>50 \%$ are shown at the branching points. Scale, $0.1 \mathrm{nt}$ substitutions per site.

\subsection{Colonization of Mycorrhizal Fungi}

The seeds of the two orchid species were co-cultivated with the three fungal strains under different concentrations of OA, and germination was monitored. Those showing protocorm formation were observed for fungal colonization under a stereomicroscope (Figure 4). The times of colonization of the three fungi were detected in orchid protocorms under different $\mathrm{OA}$ concentrations (Table 2). 
Table 2. The time of mycorrhizal fungi peloton formation was detected in orchid protocorms under different oatmeal agar (OA) concentrations (days \pm s.d.).

\begin{tabular}{ccccccc}
\hline $\begin{array}{c}\text { OA Concentrations } \\
(\mathrm{g} / \mathrm{L})\end{array}$ & Tbi & $\begin{array}{c}\text { C. mannii } \\
\text { Tas }\end{array}$ & Tca & Tbi & \multicolumn{2}{c}{$\begin{array}{c}\text { E. radicans } \\
\text { Tas }\end{array}$} \\
\hline 0.5 & $\mathrm{n}$ & $\mathrm{n}$ & $34.0 \pm 1.0$ & $\mathrm{n}$ & $\mathrm{n}$ & $25.0 \pm 0.0$ \\
1.0 & $\mathrm{n}$ & $\mathrm{n}$ & $23.0 \pm 0.0$ & $\mathrm{n}$ & $\mathrm{n}$ & $24.0 \pm 1.0$ \\
2.0 & $\mathrm{n}$ & $\mathrm{n}$ & $20.3 \pm 0.6$ & $18.3 \pm 0.6$ & $23.0 \pm 0.3$ & $20.0 \pm 1.0$ \\
4.0 & $\mathrm{n}$ & $\mathrm{n}$ & $37.0 \pm 0.0$ & $19.0 \pm 0.0$ & $22.3 \pm 0.6$ & $19.3 \pm 0.6$ \\
8.0 & $\mathrm{n}$ & $56.0 \pm 0.0$ & $55.3 \pm 0.6$ & $\mathrm{n}$ & $24.0 \pm 0.0$ & $22.0 \pm 0.3$ \\
12.0 & $\mathrm{n}$ & $56.0 \pm 0.0$ & $56.3 \pm 0.6$ & $\mathrm{n}$ & $25.0 \pm 0.0$ & $22.0 \pm 1.0$ \\
\hline
\end{tabular}

n: No symbiosis observed.

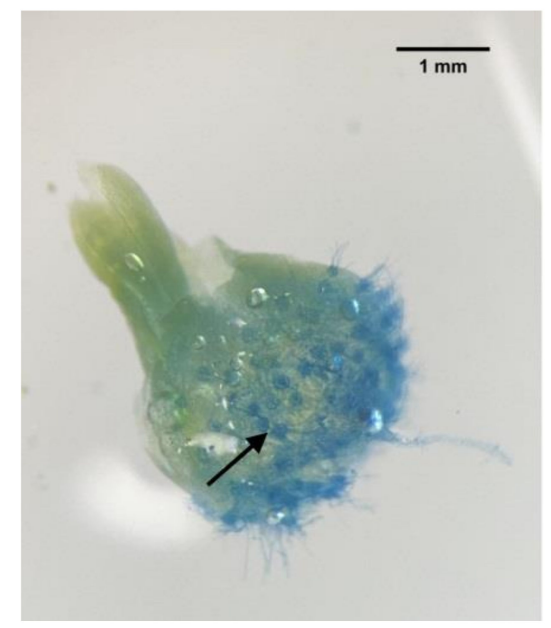

Figure 4. Fungal strain Tca colonizing and forming pelotons in a protocorm of E. radicans.

For C. mannii, Tbi could not form pelotons at any of the OA concentrations. The time of detection of Tca pelotons varied from $20.3 \pm 0.6(2.0 \mathrm{~g} / \mathrm{L} \mathrm{OA})$ to $56.3 \pm 0.6$ days $(12.0 \mathrm{~g} / \mathrm{L}$ $\mathrm{OA})$, whereas that of Tas was $56.0 \pm 0.0$ days at 8.0 and $12.0 \mathrm{~g} / \mathrm{L} \mathrm{OA}$. The peloton-forming times of the strains Tbi, Tas, and Tca in E. radicans varied depending on the concentrations of OA. The shortest time was for Tbi (18 days) at $2.0 \mathrm{~g} / \mathrm{L} \mathrm{OA}$, and the longest time was for Tas (25 days) at $12.0 \mathrm{~g} / \mathrm{L}$ OA. Tca and Tas could colonize both orchid hosts, whereas Tbi only formed pelotons in E. radicans.

\subsection{Effects of Different Fungal Strains on Seed Germination}

After 60 days of incubation, the $C$. mannii seeds co-cultivated with Tca had the highest GI value (4.16 \pm 0.21 ; Figure $5 a)$ and germination percentage (92.05 $\pm 2.45 \%$; Figure $5 c)$. The effect of Tas on C. mannii seed germination was only higher than on the CK at 8.0 and $12.0 \mathrm{~g} / \mathrm{L} \mathrm{OA}$, and only a small proportion of seeds germinated at these OA concentrations (5.06 \pm 0.56 and $10.67 \pm 0.84$, respectively; Figure 5c). Meanwhile, the GI values (Figure $5 a$ ) and seed germination percentages (Figure 5c) revealed that Tbi exhibited no evidence of promoting seed germination or seedling formation. The GI values and germination percentages of $C$. mannii seeds co-cultivated with Tca were significantly $(p<0.05)$ higher than those of the other three groups (Cm-Tas, $\mathrm{Cm}$-Tbi and $\mathrm{Cm}-\mathrm{CK}$ ) (Figure 5a,c). In terms of the successful promotion of seed germination and seedling formation, Tca exhibited a stronger effect than Tas, whereas Tbi exhibited no effect (Figure 5a,c). 


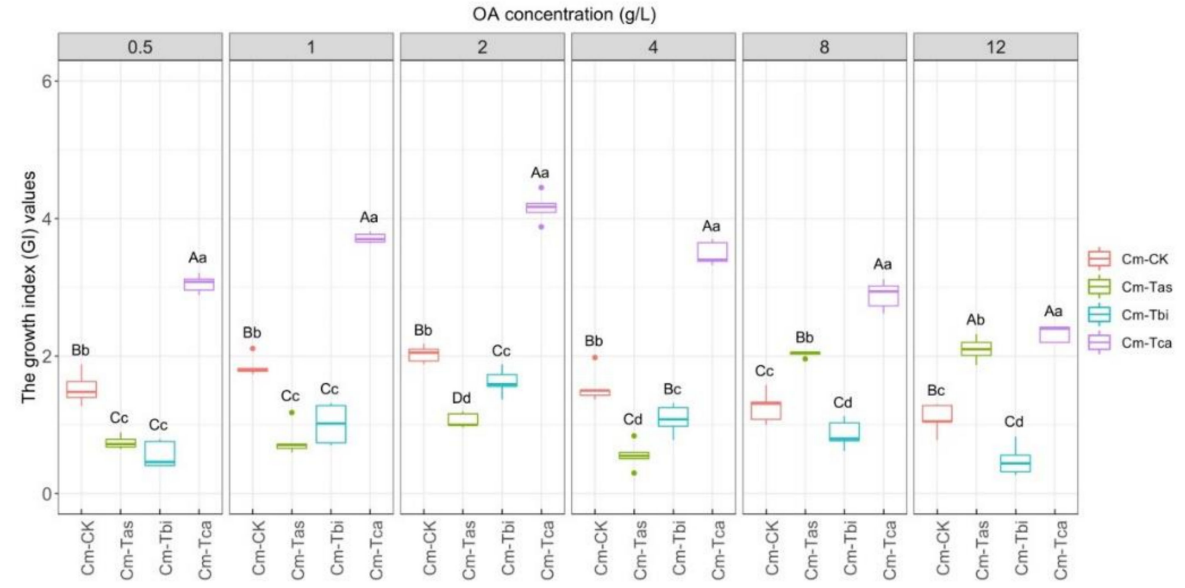

(a)

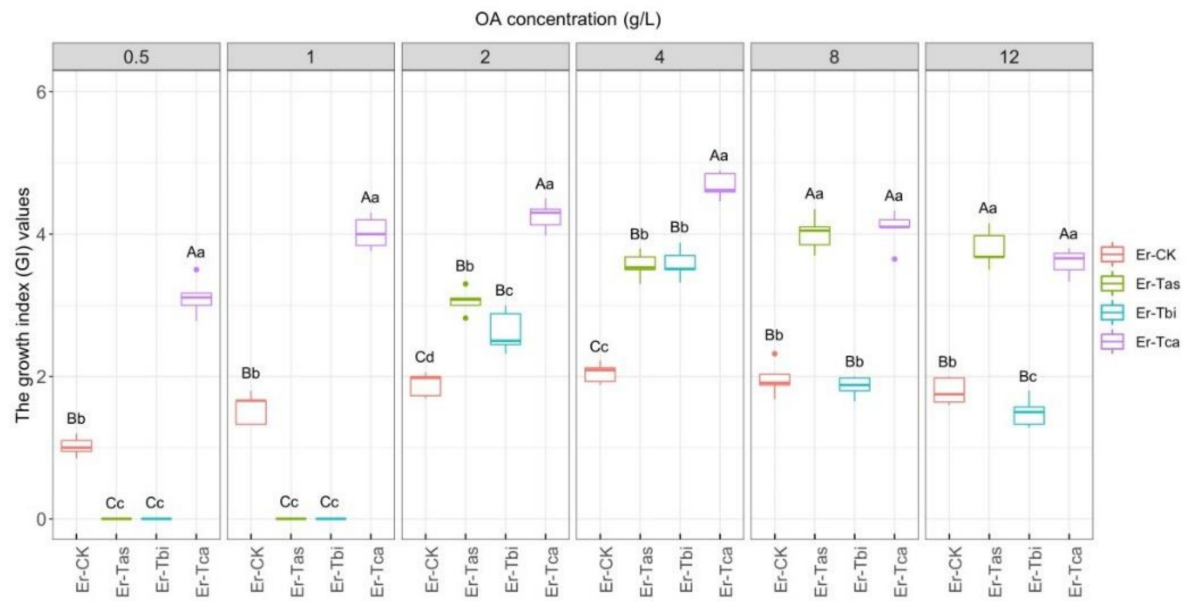

(b)

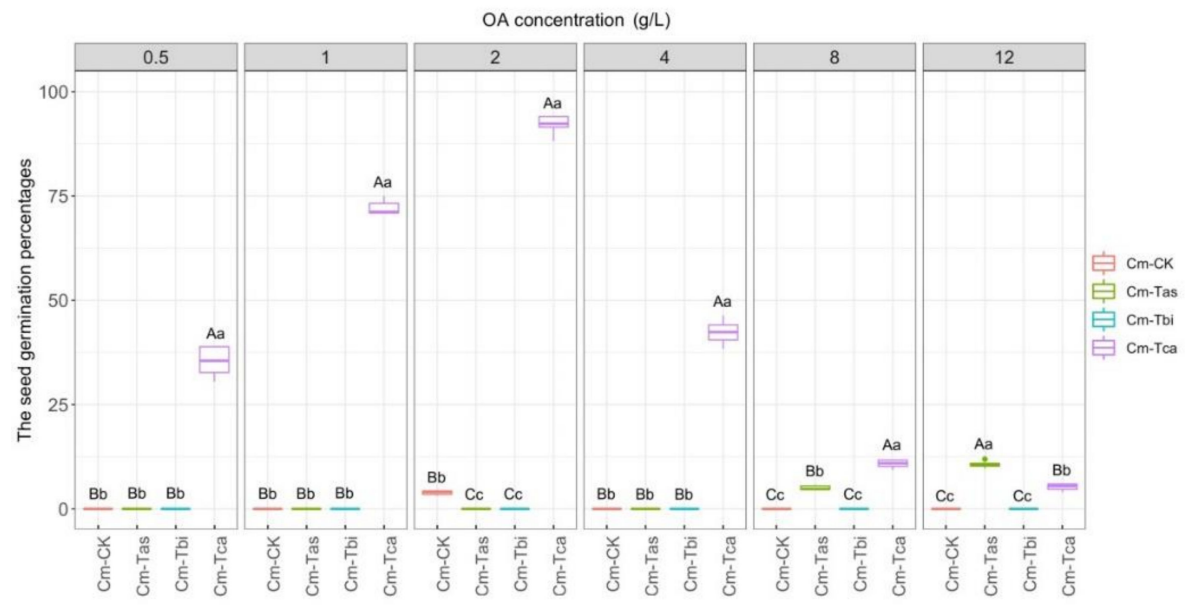

(c)

Figure 5. Cont. 


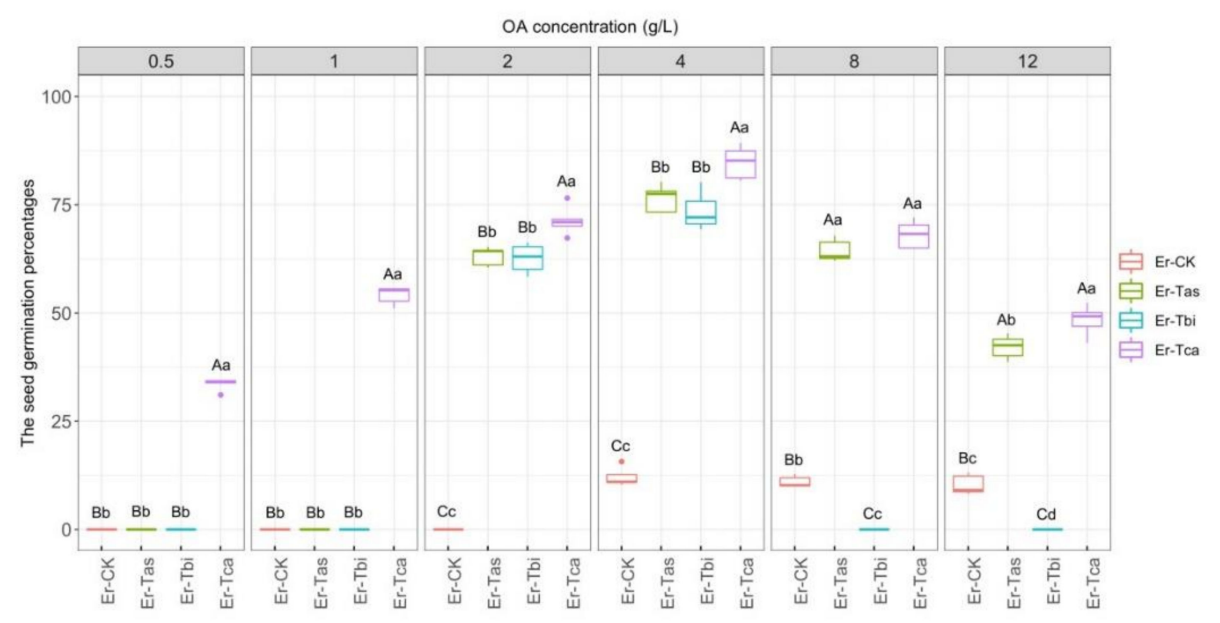

(d)

Figure 5. The effect of different fungal strains on seed germination in orchids 60 days after cultivation. (a) The growth index (GI) values of C. mannii with Tca (Cm-Tca), Tas (Cm-Tas), Tbi (Cm-Tbi), and CK (Cm-CK). (b) The GI values of E. radicans with Tca (Er-Tca), Tas (Er-Tas), Tbi (Er-Tbi), and CK (Er-CK). (c) The germination percentages of C. mannii with Tca (Cm-Tca), Tas (Cm-Tas), Tbi (Cm-Tbi), and CK (Cm-CK). (d) The germination percentages of E. radicans with Tca (Er-Tca), Tas (Er-Tas), Tbi (Er-Tbi), and CK (Er-CK). In each panel, strains with same letters are not significant; strains with different capital letters are extremely significantly different $(p<0.001)$ and lowercase letters are significantly different $(p<0.05)$ based on Tukey tests.

In E. radicans, Tca exhibited the most obvious promotional effect on seed germination, with the highest GI value (4.68 \pm 0.18 ; Figure $5 \mathrm{~b})$ and the highest proportion of seeds germinating $(84.74 \pm 3.83 \%$; Figure $5 \mathrm{~d})$. Tas had a better germination-promoting effect; it promoted seed germination at four OA concentrations $(2.0,4.0,8.0$, and $12.0 \mathrm{~g} / \mathrm{L})$, with the highest value being $76.49 \pm 3.14 \%$ on $4.0 \mathrm{~g} / \mathrm{L} \mathrm{OA}$; (Figure $5 \mathrm{~d}$ ). Tbi caused seed expansion and germination at 2.0-12.0 g/L OA; however, this strain could not support the seeds in completing subsequent stages of germination and becoming seedlings at the two higher OA concentrations ( 8.0 and $12.0 \mathrm{~g} / \mathrm{L}$ ); its GI value was lower than that of the CK group and the germination percentage was zero. The highest GI values of Tca were significantly $(p<0.05)$ higher than those of the other three groups at four concentrations of OA $(0.5,1.0$, 2.0 , and $4.0 \mathrm{~g} / \mathrm{L}$ ); however, they were not significantly higher than those of Tas on 8.0 and $12.0 \mathrm{~g} / \mathrm{L} \mathrm{OA}$ (Figure $5 \mathrm{~b}$ ). Considering the seed germination percentages, Tca performed significantly $(p<0.05)$ better than the other three strains, but the result was not significantly different from that of Tas on $8.0 \mathrm{~g} / \mathrm{L} \mathrm{OA}$. No significant differences were observed between the seed germination percentages of Tas and Tbi on 0.5, 1.0, 2.0, or $4.0 \mathrm{~g} / \mathrm{L} \mathrm{OA}$; however, Tas performed significantly better $(p<0.001)$ than Tbi on 8.0 and $12.0 \mathrm{~g} / \mathrm{L} \mathrm{OA}$ (Figure $5 \mathrm{~d}$ ).

\subsection{Effects of Different Concentrations of OA on Seed Germination}

The concentration of the co-culture medium played an important role in determining symbiosis and its effects. For C. mannii, Tca could promote seed germination at all six OA concentrations; the germination percentage varied from $5.23 \pm 0.86 \%(12.0 \mathrm{~g} / \mathrm{L} \mathrm{OA})$ to 92.05 $\pm 2.45 \%$ (2.0 g/L OA; Figure $6 \mathrm{~b})$, and the GI values varied from $2.33 \pm 0.12(12.0 \mathrm{~g} / \mathrm{L} \mathrm{OA})$ to $4.16 \pm 0.21$ (2.0 g/L OA; Figure $6 \mathrm{a})$. The GI values and germination percentages of Tca in C. mannii were significantly $(p<0.001)$ higher on $2.0 \mathrm{~g} / \mathrm{L} \mathrm{OA}$ than at other concentrations (Figure $6 \mathrm{a}, \mathrm{b}$ ). The GI values of the symbiotic Tas groups at two OA concentrations, 8.0 $\mathrm{g} / \mathrm{L}$ and $12.0 \mathrm{~g} / \mathrm{L}$, did not differ significantly, but both values were significantly $(p<0.001)$ higher than those at the other four OA concentrations (Figure 6a).

When the three fungal strains were grown symbiotically with $E$. radicans, the seed germination rates on $4.0 \mathrm{~g} / \mathrm{L} \mathrm{OA}(84.74 \pm 3.83 \%$ for Tca, $73.60 \pm 4.42 \%$ for Tbi, and $76.49 \pm$ $3.14 \%$ for Tas) were significantly $(p<0.001)$ higher than those at other OA concentrations. For Tas and Tbi, the seeds did not germinate at certain concentrations of OA (Tas: 0.5 and $1.0 \mathrm{~g} / \mathrm{L}$; Tbi: $0.5,1.0,8.0$, and $12.0 \mathrm{~g} / \mathrm{L} \mathrm{OA}$; Figure $6 \mathrm{c}, \mathrm{d}$ ). 


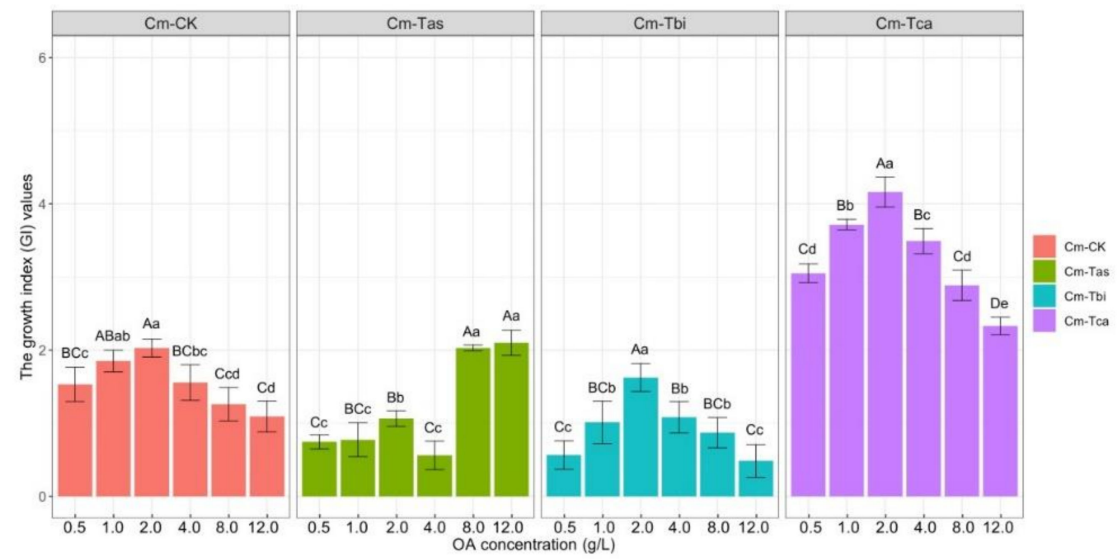

(a)

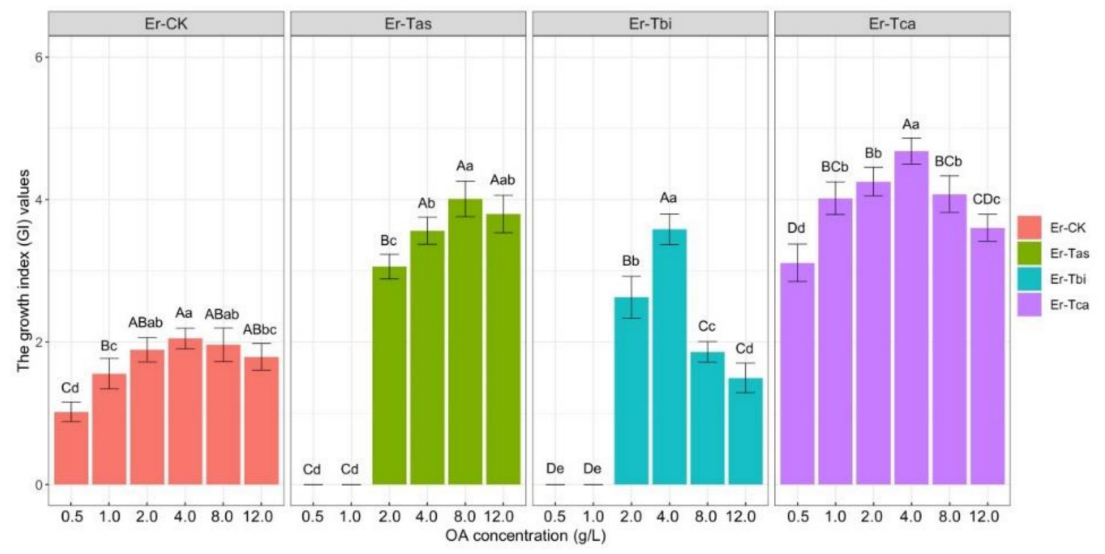

(b)

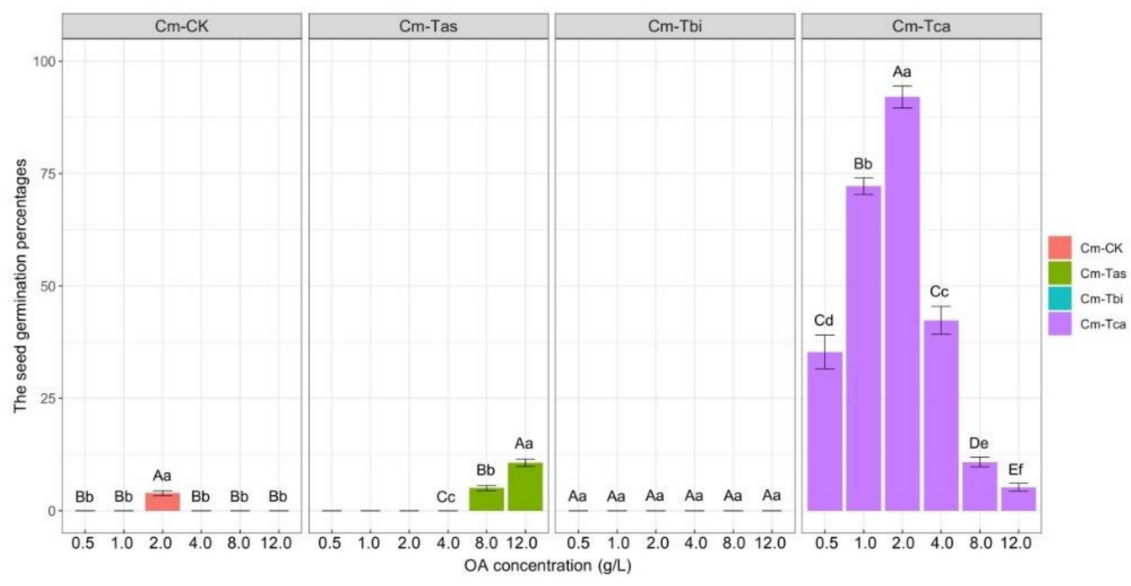

(c)

Figure 6. Cont. 


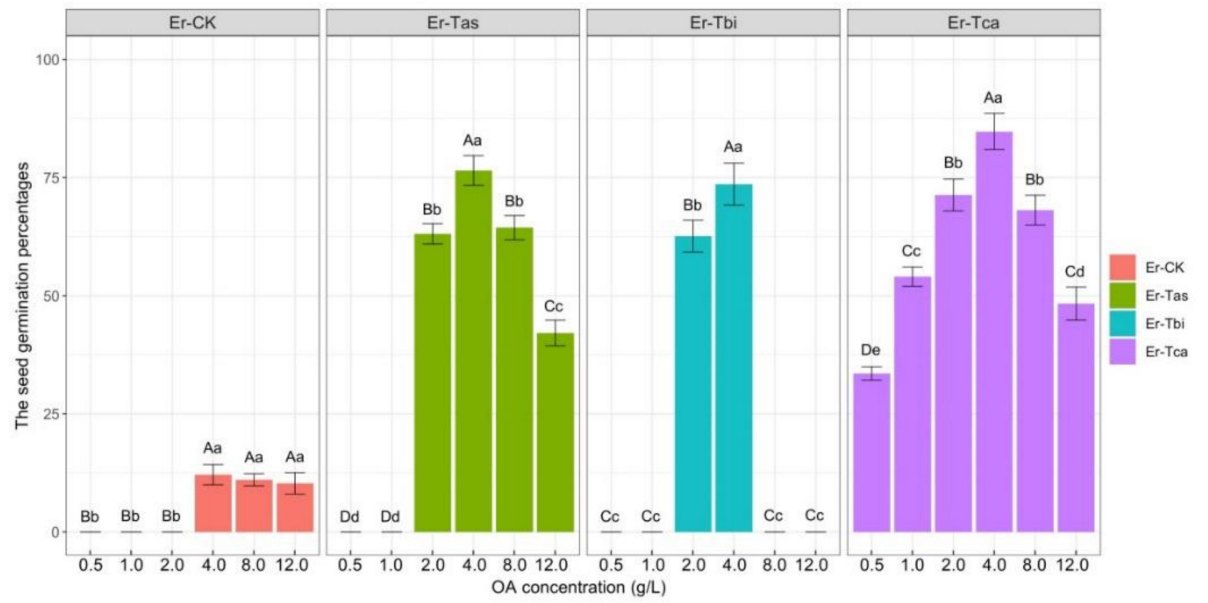

Figure 6. The effects of different concentrations of OA on seed germination 60 days after cultivation. (a) The GI values of $C$. mannii with Tca (Cm-Tca), Tas (Cm-Tas), Tbi (Cm-Tbi), and CK (Cm-CK). (b) The GI values of E. radicans with Tca (Er-Tca), Tas (Er-Tas), Tbi (Er-Tbi), and CK (Er-CK). (c) The germination percentages of C. mannii with Tca (Cm-Tca), Tas (Cm-Tas), Tbi (Cm-Tbi), and CK (Cm-CK). (d) The germination percentages of E. radicans with Tca (Er-Tca), Tas (Er-Tas), Tbi (Er-Tbi), and CK (Er-CK). In each panel, concentrations with same letters are not significant; concentrations with different capital letters are extremely significantly different $(p<0.001)$ and lowercase letters are significantly different $(p<0.05)$ based on Tukey tests.

\section{Discussion}

Orchid growth depends on various environmental factors, including temperature, soil type, competition, pollination, and the presence of mycorrhizal fungi [9,43-45]. Mycorrhizal fungi are essential for the successful symbiotic development of orchids under natural conditions, upon reintroduction of endangered orchid species to their natural environment, and in the cultivation of ornamental and medicinal species [27,44,46,47].

Most symbiotic fungi found in orchids are within the 'rhizoctonia' species complex [6, 48], which includes the Ceratobasidiaceae and Tulasnellaceae in the Cantharellales and the Serendipitaceae in the Sebacinales [49-52]. Despite a lack of references concerning the teleomorphic states of Tulasnella, molecular tools can be effectively applied to identify the strains; phylogeny based on ITS sequences was found to be better resolved than $m t L S U$ phylogeny for identifying the Tulasnella genus [53]. In our study, three fungal isolates were obtained from three species of orchids. They were identified as Tulasnella using ITS-5.8S rDNA sequence analysis, and the phylogenetic trees showed that the three strains belonged to three clusters. Based on the results of the molecular analysis, we proceeded to establish mycorrhizal symbiosis with orchids using the three mycorrhizal strains and attempted to understand the relationships between Tulasnella and orchids. Under suitable external conditions, fungi recognize plants and subsequently establish symbiosis. The compatibility between orchids and their mycorrhizal fungi is variable and influenced by the surrounding plant species and environmental conditions [20,44,53]. It is generally believed that orchid mycorrhizal fungi show a certain degree of compatibility with species other than their hosts [54]. Some orchid species can maintain contact with a single fungal strain, while others can establish contact with different strains at different growth stages [55]. The evolutionary mechanisms of the interaction relationships of species involved in such broad interactions is likely to be "apparent generalism", which is defined as "one species is specific to one or several host species that provide unique resources, but it is also related to other host species that provide functional redundant resources, and the phylogeny of orchid plants may be an important determinant of fungal association" [55]. In this study, the Tca strain isolated from the roots of C. mannii successfully established symbiosis and promoted seed germination in both C. mannii and $E$. radicans. In other words, strain Tca was compatible with the orchid species examined in this study. Strain Tas, isolated from E. radicans (an epiphytic orchid), also could establish symbiosis 
and promote seed germination in the above two species of orchids; however, compared with Tca, its colonization took longer and even failed at certain OA concentrations. Strain Tbi, isolated from C. goeringii (a terrestrial orchid), could promote seed germination in E. radicans only on 2.0 and $4.0 \mathrm{~g} / \mathrm{L} \mathrm{OA}$; however, it had no germination-promoting effects in C. mannii. These results suggest that fungal strains present a certain degree of compatibility with various orchids, and are also affected by the environment.

High compatibility contributes to beneficial associations between fungi and orchids, promoting seed germination and protocorm development. However, these beneficial reactions are easily affected by several ecological factors, such as nutrients, photoperiod, temperature, and plant hormones [24]. Nutrient concentration plays an important role in mycorrhizal fungi-induced promotion of germination and its symbiotic relationship with orchid seeds. It has a long been understood that orchids receive not only mineral nutrients, such as $\mathrm{N}$ and $\mathrm{P}$, but also organic $\mathrm{C}$ from orchid mycorrhizal fungi without rewards during germination $[56,57]$. Studies have examined the symbiotic promotion of orchid seed germination by mycorrhizal fungi using OA [28].

Because OA has the advantages of a controllable nutrient concentration and simple operation, we used mediums with different oatmeal concentrations to illustrate their effects on seed germination. The results show that germination percentages varied with oatmeal concentration under the same strain conditions. Tas promoted the seed germination of C. mannii at 8.0 and $12.0 \mathrm{~g} / \mathrm{L} \mathrm{OA}$ but not on other OA concentrations. However, Tca promoted seed germination in both $C$. mannii and E. radicans under all OA concentrations used in this study.

Fungi compatible with orchid plants may colonize orchid protocorms to form pelotons, after which, the protocorms may develop into photosynthetic seedlings. However, the orchid protocorms may also be overgrown by the fungal mycelium, and this can eventually lead to rot and death [52,57]. It is speculated that when nutrients are abundant or too scarce to meet the needs of seed germination and growth, fungi tend to live in saprophytic rather than symbiotic conditions with plants [52,57]. Recent work has shown that orchid mycorrhizal fungi may have more genes involved in the degradation of plant cell wall components than other mycorrhizal types [58]. The expression of CAZyme genes, which were identified in the process of establishing symbiotic relationships between T. calospora and two orchid species (Serapias vomeracea and Cattleya purpurata), showed that the degradative potential of T. calospora could possibly participate in regulating a switch between saprotrophic growth and symbiosis [52]. However, the mechanisms leading to mycorrhizal fungus transition between the mycorrhizal and saprotrophic stages are complex and need to be further elucidated [52].

In this study, the optimal fungal strains and culture media for efficient symbiosis were determined in two orchid plants. The results provide a technical reference for further studies on the molecular mechanism of orchid symbiosis in vitro and can be applied to the protection of orchid plant resources.

\section{Conclusions}

In this study, three fungal strains were isolated from the roots of different orchid plants and were identified as Tulasnella based on their ITS-rDNA sequences. The compatibility and germination-promoting activities of these fungi were investigated at different $\mathrm{OA}$ concentrations. In germination trials under laboratory conditions, the strain Tca exhibited the best compatibility and germination-promoting effects on both C. mannii and E. radicans, and all three fungal strains used in this study could promote seed germination in $E$. radicans. Moreover, the concentration of oatmeal in the medium affected the compatibility and germination-promoting activity of the fungi. These findings indicate that orchid mycorrhizal fungi present a certain degree of compatibility with various orchid plants, and are affected by the environment. These results may pave the way for further research on mycorrhizal technology in orchid propagation for conservation and commercial purposes. 
Author Contributions: Conceptualization, L.L. (Lei Liu) and L.X. (Lu Xu); methodology, L.L. (Liu Lei) and X.B.; validation, X.B. and L.L. (Lixiong Liang).; formal analysis, L.X. (Lijun Xu) and L.L. (Lixiong Liang); investigation, Q.Y.; resources, L.L. (Lubin Li); data curation, W.X.; writing-original draft preparation, L.L. (Liu Lei); writing-review and editing, L.X. (Lu Xu); supervision, L.L. (Liu Lei); funding acquisition, L.L. (Liu Lei) and L.X. ( $\mathrm{Lu} \mathrm{Xu).} \mathrm{All} \mathrm{authors} \mathrm{have} \mathrm{read} \mathrm{and} \mathrm{agreed} \mathrm{to} \mathrm{the}$ published version of the manuscript.

Funding: This work was funded by the National Natural Science Foundation of China, grant number No. 31800522, and the project was supported by the Scientific Research Fund of Hunan Provincial Education Department, grant number No. 18B101 and the Hunan Provincial Natural Science Foundation of China, grant number No. 2019JJ50232.

Institutional Review Board Statement: Not applicable.

Informed Consent Statement: Not applicable.

Acknowledgments: We thank Jinjun Yue for his suggestions regarding the choice of culture media and data processing and Xinmiao Liu for her help in drawing figures for this paper.

Conflicts of Interest: The authors declare no conflict of interest.

\section{References}

1. Stokstad, E. Orchids' dazzling diversity explained. Science 2015, 349, 914. [CrossRef]

2. Rafter, M.; Yokoya, K.; Schofield, E.J.; Zettler, L.W.; Sarasan, V. Non-specific symbiotic germination of Cynorkis purpurea (Thouars) Kraezl., a habitat-specific terrestrial orchid from the Central Highlands of Madagascar. Mycorrhiza 2016, 26, 541-552. [CrossRef]

3. Suetsugu, K.; Kawakita, A.; Kato, M. Avian seed dispersal in a mycoheterotrophic orchid Cyrtosia septentrionalis. Nat. Plants 2015, 1. [CrossRef]

4. Sheng, C.-L.; Lee, Y.-I.; Gao, J.-Y. Ex situ symbiotic seed germination, isolation and identification of effective symbiotic fungus in Cymbidium mannii (Orchidaceae). Chin. J. Plant Ecol. 2012, 36, 859-869. [CrossRef]

5. Clements, M.A. Orchid mycorrhizal associations. Lindleyana 1988, 3, 73-86.

6. Rasmussen, H.; Rasmussen, F.N. Orchid mycorrhiza: Implications of a mycophagous life style. Oikos 2009, 118, 334-345. [CrossRef]

7. Khamchatra, N.-M.; Dixon, K.; Chayamarit, K.; Apisitwanich, S.; Tantiwiwat, S. Using in situ seed baiting technique to isolate and identify endophytic and mycorrhizal fungi from seeds of a threatened epiphytic orchid, Dendrobium friedericksianum Rchb.f. (Orchidaceae). Agric. Nat. Resour. 2016, 50, 8-13. [CrossRef]

8. Zettler, L.W.; Poulter, S.B.; McDonald, K.I.; Stewart, S.L. Conservation-driven Propagation of an Epiphytic Orchid (Epidendrum nocturnum) with a Mycorrhizal Fungus. HortScience 2007, 42, 135-139. [CrossRef]

9. Swarts, N.D.; Dixon, K. Terrestrial orchid conservation in the age of extinction. Ann. Bot. 2009, 104, 543-556. [CrossRef] [PubMed]

10. Meng, Y.-Y.; Shao, S.-C.; Liu, S.-J.; Gao, J.-Y. Do the fungi associated with roots of adult plants support seed germination? A case study on Dendrobium exile (Orchidaceae). Glob. Ecol. Conserv. 2019, 17, e00582. [CrossRef]

11. Durán-López, M.; Caroca-Cáceres, R.; Jahreis, K.; Narváez-Vera, M.; Ansaloni, R.; Cazar, M. The micorryzal fungi Ceratobasidium sp. and Sebacina vermifera promote seed germination and seedling development of the terrestrial orchid Epidendrum secundum Jacq. South Afr. J. Bot. 2019, 125, 54-61. [CrossRef]

12. Selosse, M.-A.; Faccio, A.; Scappaticci, G.; Bonfante, P. Chlorophyllous and Achlorophyllous Specimens of Epipactis microphylla (Neottieae, Orchidaceae) Are Associated with Ectomycorrhizal Septomycetes, including Truffles. Microb. Ecol. 2004, 47, 416-426. [CrossRef]

13. Kottke, I.; Suárez, J.P.; Herrera, P.; Cruz, D.; Bauer, R.; Haug, I.; Garnica, S. Atractiellomycetes belonging to the 'rust' lineage (Pucciniomycotina) form mycorrhizae with terrestrial and epiphytic neotropical orchids. Proc. R. Soc. B Boil. Sci. 2009, 277, 1289-1298. [CrossRef]

14. Riofrío, M.L.; Cruz, D.; Torres, E.; De La Cruz, M.; Iriondo, J.M.; Suárez, J.P. Mycorrhizal preferences and fine spatial structure of the epiphytic orchid Epidendrum rhopalostele. Am. J. Bot. 2013, 100, 2339-2348. [CrossRef] [PubMed]

15. Gao, Y.; Guo, S.-X.; Xing, X.-K. Fungal diversity and mechanisms of symbiotic germination of orchid seeds: A review. MycoSystema 2019, 38, 1808-1825. (In Chinese) [CrossRef]

16. Bidartondo, M.I.; Read, D.J. Fungal specificity bottlenecks during orchid germination and development. Mol. Ecol. 2008, 17, 3707-3716. [CrossRef] [PubMed]

17. Davis, B.J.; Phillips, R.D.; Wright, M.; Linde, C.; Dixon, K. Continent-wide distribution in mycorrhizal fungi: Implications for the biogeography of specialized orchids. Ann. Bot. 2015, 116, 413-421. [CrossRef]

18. Bayman, P.; Mosquera-Espinosa, A.T.; Saladini-Aponte, C.M.; Hurtado-Guevara, N.C.; Viera-Ruiz, N.L. Age-dependent mycorrhizal specificity in an invasive orchid, Oeceoclades maculata. Am. J. Bot. 2016, 103, 1880-1889. [CrossRef] [PubMed]

19. Xing, X.; Ma, X.; Men, J.; Chen, Y.; Guo, S. Phylogenetic constrains on mycorrhizal specificity in eight Dendrobium (Orchidaceae) species. Sci. China Life Sci. 2017, 60, 536-544. [CrossRef] 
20. Reiter, N.; Reiter, N.; Phillips, R.D.; Phillips, R.D.; Swarts, N.D.; Swarts, N.D.; Wright, M.; Wright, M.; Holmes, G.; Holmes, G.; et al. Specific mycorrhizal associations involving the same fungal taxa in common and threatened Caladenia (Orchidaceae): Implications for conservation. Ann. Bot. 2020, 126, 943-955. [CrossRef]

21. Jacquemyn, H.; Honnay, O.; Cammue, B.P.A.; Brys, R.; Lievens, B. Low specificity and nested subset structure characterize mycorrhizal associations in five closely related species of the genus Orchis. Mol. Ecol. 2010, 19, 4086-4095. [CrossRef] [PubMed]

22. Stewart, S.L.; Zettler, L.W.; Minso, J.; Brown, P.M. Symbiotic germination and reintroduction of Spiranthes brevilabris Lindley, an endangered orchid native to Florida. Selbyana 2003, 24, 64-70.

23. Perotto, S.; Rodda, M.; Benetti, A.; Sillo, F.; Ercole, E.; Rodda, M.; Girlanda, M.; Murat, C.; Balestrini, R. Gene expression in mycorrhizal orchid protocorms suggests a friendly plant-fungus relationship. Planta 2014, 239, 1337-1349. [CrossRef]

24. Øien, D.-I.; O’Neill, J.P.; Whigham, D.F.; McCormick, M.K. Germination Ecology of the Boreal-Alpine Terrestrial Orchid Dactylorhiza lapponica (Orchidaceae). Ann. Bot. Fenn. 2008, 45, 161-172. [CrossRef]

25. Zhou, X.; Gao, J. Highly compatible Epa-01 strain promotes seed germination and protocorm development of Papilionanthe teres (Orchidaceae). Plant Cell Tissue Organ Cult. 2016, 125, 479-493. [CrossRef]

26. Tan, X.M.; Wang, C.L.; Chen, X.M.; Zhou, Y.Q.; Wang, Y.Q.; Luo, A.X.; Liu, Z.H.; Guo, S.X. In vitro seed germination and seedling growth of an endangered epiphytic orchid, Dendrobium officinale, endemic to China using mycorrhizal fungi (Tulasnella sp.). Sci. Hortic. 2014, 165, 62-68. [CrossRef]

27. Nontachaiyapoom, S.; Sasirat, S.; Manoch, L. Symbiotic seed germination of Grammatophyllum speciosum Blume and Dendrobium draconis Rchb. f., native orchids of Thailand. Sci. Hortic. 2011, 130, 303-308. [CrossRef]

28. Mala, B.; Kuegkong, K.; Sa-Ngiaemsri, N.; Nontachaiyapoom, S. Effect of germination media on in vitro symbiotic seed germination of three Dendrobium orchids. South Afr. J. Bot. 2017, 112, 521-526. [CrossRef]

29. Xu, L.; Tian, J.N.; Wang, T.; Li, L.B. Symbiosis established between orchid and Tulasnella spp. fungi. J. Nucl. Agric. Sci. 2017, 31, 876-883. (In Chinese) [CrossRef]

30. Motomura, H.; Yukawa, T.; Ueno, O.; Kagawa, A. The occurrence of crassulacean acid metabolism in Cymbidium (Orchidaceae) and its ecological and evolutionary implications. J. Plant Res. 2008, 121, 163-177. [CrossRef]

31. Zhe, M.; Zhang, L.; Liu, F.; Huang, Y.; Fan, W.; Yang, J.; Zhu, A. Plastid RNA editing reduction accompanied with genetic variations in Cymbidium, a genus with diverse lifestyle modes. Plant Divers. in press. 2021. [CrossRef]

32. Wei, J.F.; Cen, Z.Y.; Su, J. Effects of different mediums on the growth of tissue culture seedling of Cymbidium bicolor Lindl during stemporary planting period. Northern Hortic. 2012, 23, 59-61. (In Chinese)

33. Thwala, M.; Wahome, P.K.; Oseni, T.O.; Masarirambi, M.T. Effects of floral preservatives on the vase life of orchid (Epidendrum radicans L.) cut flowers. J. Hort. Sci. Ornament. Plants 2013, 5, 22-29. [CrossRef]

34. Huang, H.; Zi, X.-M.; Lin, H.; Gao, J.-Y. Host-specificity of symbiotic mycorrhizal fungi for enhancing seed germination, protocorm formation and seedling development of over-collected medicinal orchid, Dendrobium devonianum. J. Microbiol. 2018, 56, 42-48. [CrossRef] [PubMed]

35. Zhang, Y.; Li, Y.-Y.; Chen, X.-M.; Guo, S.-X.; Lee, Y.-I. Effect of different mycobionts on symbiotic germination and seedling growth of Dendrobium officinale, an important medicinal orchid. Bot. Stud. 2020, 61, 1-10. [CrossRef] [PubMed]

36. Fracchia, S.; Rickert, A.M.A.; Flachsland, E.; Terada, G.; Sede, S.M. Mycorrhizal compatibility and symbiotic reproduction of Gavilea australis, an endangered terrestrial orchid from south Patagonia. Mycorrhiza 2014, 24, 627-634. [CrossRef]

37. Wang, D.; Jia, S.H.; Zhang, Z.X.; Cai, Y.P.; Lin, Y. Isolation and culture of an endophytic fungus associated with Dendrobium huoshanense and its effects on the growth of plantlets. J. Fungal. Res. 2007, 5, 84-88. (In Chinese)

38. Kumar, S.; Stecher, G.; Li, M.; Knyaz, C.; Tamura, K.; Battistuzzi, F.U. MEGA X: Molecular Evolutionary Genetics Analysis across Computing Platforms. Mol. Biol. Evol. 2018, 35, 1547-1549. [CrossRef] [PubMed]

39. Seaton, P.T.; Hu, H.; Perner, H.; Pritchard, H.W. Ex Situ Conservation of Orchids in a Warming World. Bot. Rev. 2010, 76, 193-203. [CrossRef]

40. Zhao, X.-L.; Yang, J.-Z.; Liu, S.; Chen, C.-L.; Zhu, H.-Y.; Cao, J.-X. The colonization patterns of different fungi on roots of Cymbidium hybridum plantlets and their respective inoculation effects on growth and nutrient uptake of orchid plantlets. World J. Microbiol. Biotechnol. 2014, 30, 1993-2003. [CrossRef]

41. Otero, J.T.; Ackerman, J.D.; Bayman, P. Differences in mycorrhizal preferences between two tropical orchids. Mol. Ecol. 2004, 13, 2393-2404. [CrossRef]

42. Jiang, J.-H.; Lee, Y.-I.; Cubeta, M.A.; Chen, L.-C. Characterization and colonization of endomycorrhizal Rhizoctonia fungi in the medicinal herb Anoectochilus formosanus (Orchidaceae). Mycorrhiza 2015, 25, 431-445. [CrossRef]

43. Huber, F.K.; Kaiser, R.; Sauter, W.; Schiestl, F.P. Floral scent emission and pollinator attraction in two species of Gymnadenia (Orchidaceae). Oecologia 2004, 142, 564-575. [CrossRef]

44. Herrera, H.; Valadares, R.; Contreras, D.; Bashan, Y.; Arriagada, C. Mycorrhizal compatibility and symbiotic seed germination of orchids from the Coastal Range and Andes in south central Chile. Mycorrhiza 2016, 27, 175-188. [CrossRef] [PubMed]

45. Gregg, K.B.; Kéry, M. Comparison of size vs. life-state classification in demographic models for the terrestrial orchid Cleistes bifaria. Biol. Conserv. 2006, 129, 50-58. [CrossRef]

46. Chen, J.; Wang, H.; Guo, S.-X. Isolation and identification of endophytic and mycorrhizal fungi from seeds and roots of Dendrobium (Orchidaceae). Mycorrhiza 2011, 22, 297-307. [CrossRef] [PubMed] 
47. Pereira, G.; Romero, C.; Suz, L.M.; Atala, C. Essential mycorrhizal partners of the endemic Chilean orchids Chloraea collicensis and C. gavilu. Flora 2014, 209, 95-99. [CrossRef]

48. Dearnaley, J.D.W. Further advances in orchid mycorrhizal research. Mycorrhiza 2007, 17, 475-486. [CrossRef]

49. Warcup, J.H.; Talbot, P.H.B. Perfect states of Rhizoctonias associated with orchids. New Phytol. 1967, 66, 631-641. [CrossRef]

50. Moore, R.T. The genera of Rhizoctonia-like fungi: Ascorhizoctonia, Ceratorhiza gen. nov., Epulorhiza gen. nov., Moniliopsis, and Rhizoctonia. Mycotaxon 1987, 29, 91-99.

51. Zi, X.-M.; Sheng, C.-L.; Goodale, U.; Shao, S.-C.; Gao, J.-Y. In situ seed baiting to isolate germination-enhancing fungi for an epiphytic orchid, Dendrobium aphyllum (Orchidaceae). Mycorrhiza 2014, 24, 487-499. [CrossRef] [PubMed]

52. Adamo, M.; Chialva, M.; Calevo, J.; De Rose, S.; Girlanda, M.; Perotto, S.; Balestrini, R. The Dark Side of Orchid Symbiosis: Can Tulasnella calospora Decompose Host Tissues? Int. J. Mol. Sci. 2020, 21, 3139. [CrossRef]

53. McCormick, M.K.; Taylor, D.L.; Juhaszova, K.; Burnett, R.K.; Whigham, D.F.; O'Neill, J.P. Limitations on orchid recruitment: Not a simple picture. Mol. Ecol. 2012, 21, 1511-1523. [CrossRef] [PubMed]

54. Calevo, J.; Voyron, S.; Ercole, E.; Girlanda, M. Is the Distribution of Two Rare Orchis Sister Species Limited by Their Main Mycobiont? Diversity 2020, 12, 262. [CrossRef]

55. Shefferson, R.P.; Bunch, W.; Cowden, C.C.; Lee, Y.; Kartzinel, T.R.; Yukawa, T.; Downing, J.; Jiang, H. Does evolutionary history determine specificity in broad ecological interactions? J. Ecol. 2019, 107, 1582-1593. [CrossRef]

56. McCormick, M.K.; Whigham, D.F.; Canchani-Viruet, A. Mycorrhizal fungi affect orchid distribution and population dynamics. New Phytol. 2018, 219, 1207-1215. [CrossRef] [PubMed]

57. Yeh, C.-M.; Chung, K.; Liang, C.-K.; Tsai, W.-C. New Insights into the Symbiotic Relationship between Orchids and Fungi. Appl. Sci. 2019, 9, 585. [CrossRef]

58. Miyauchi, S.; Kiss, E.; Kuo, A.; Drula, E.; Kohler, A.; Sánchez-García, M.; Morin, E.; Andreopoulos, B.; Barry, K.W.; Bonito, G.; et al. Large-scale genome sequencing of mycorrhizal fungi provides insights into the early evolution of symbiotic traits. Nat. Commun. 2020, 11, 5125-5142. [CrossRef] [PubMed] 